\title{
Modeling Wood Gasification in a Countercurrent Fixed-Bed Reactor
}

\author{
Colomba Di Blasi \\ Dipartimento di Ingegneria Chimica, Università degli Studi di Napoli "Federico II," 80125 Napoli, Italy
}

DOI 10.1002/aic.10189

Published online in Wiley InterScience (www.interscience.wiley.com).

\begin{abstract}
A one-dimensional, unsteady mathematical model is presented of fixed-bed countercurrent wood gasifiers, which couples heat and mass transport with wood drying and devolatilization, char gasification, and combustion of both char and gas-phase species. The model is used to simulate the structure of the reaction fronts and the gasification behavior of a laboratory-scale plant as the reactor throughput and the air-to-wood (or char) weight ratio are varied. It is observed that a wide zone, acting essentially as a countercurrent heat exchanger, separates combustion/gasification from devolatilization/ drying. Moreover, the former zone presents interesting dynamic patterns driven by the highly variable solid/gas heat transfer rates. For a constant air-to-wood weight ratio, the gasification process is improved by increasing the reactor throughput as a result of higher temperatures, in spite of the simultaneous reduction in the amount of char generated from wood devolatilization. In fact, an increase in the air-to-wood (or char) ratio always lowers the efficiency of the gasification process. Finally, good agreement is obtained between predictions and experiments for the axial temperature profiles and the composition of the producer gas. (ㅇ 2004 American Institute of Chemical Engineers AIChE J, 50: 2306-2319, 2004

Keywords: modeling, wood, gasification, fixed-bed reactor
\end{abstract}

\section{Introduction}

Gasification is an important technology widely applied for solid-gas reactions of coal and biomass. Large-scale development and optimization require mathematical modeling thatallowing quantitative representation of various phenomena-is a powerful tool for process design, prediction of gasifier performances, understanding of evolution of pollutants, analysis of process transients, and examination of strategies for effective control. Numerous models have been proposed for fixedbed reactors, given that this technology is applied for $89 \%$ of the coal gasified in the world (entrained beds contribute $10 \%$ and fluid-beds only 1\%) (Radulovic et al., 1995). Previously, the state of the art for coal conversion was carefully reviewed by the Advanced Combustion Engineering Research Center of

Correspondence concerning this article should be addressed to C. Di Blasi at diblasi@unina.it.

(C) 2004 American Institute of Chemical Engineers the Brigham Young University (Provo, UT) (Hobbs et al., 1993). The common features adopted by the different models were identified and include:

(1) single shape and size of the particles;

(2) no momentum transfer;

(3) constant porosity of the bed;

(4) heat and mass transfer coefficients for nonreacting systems;

(5) instantaneous drying;

(6) instantaneous or highly simplified solid devolatilization;

(7) uncertainty on the intrinsic kinetics of heterogeneous combustion and gasification reactions;

(8) no homogeneous gas-phase reaction, apart from the water-gas shift equilibrium;

(9) steady, one-dimensional equations; and

(10) limited model sensitivity analysis and validation.

The authors of the review also point out that "model development has not reached the point where significant use is made in process development for coal utilization," but some successive 


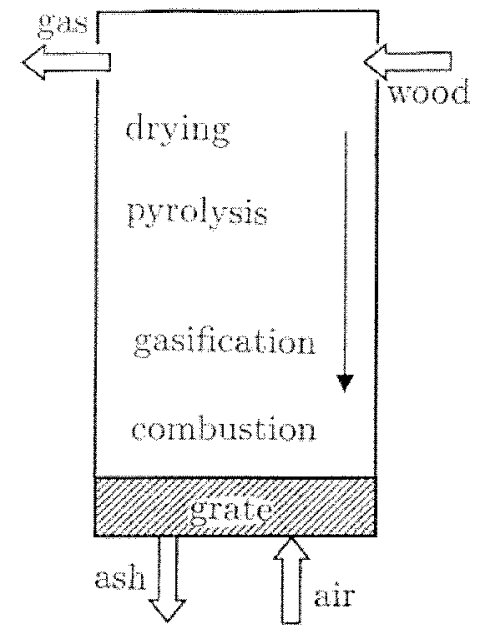

Figure 1. Countercurrent (updraft) wood gasifier.

analyses presented by the same research group (Ghani et al., 1996; Radulovic et al., 1995) have contributed significantly to this issue through models that remove assumptions 3, 5, 6, and 10. Also, the most recent study by Monazam and Shadle (1998), aimed at the formulation of engineering correlations for countercurrent coal gasification, should be mentioned.

A very few models have been proposed for biomass gasification. Heterogeneous reaction kinetics and transport phenomena have been considered by Groeneveld and van Swaaij (1980), Manurung and Beenackers (1994), and Di Blasi (2000). All these analyses are for concurrent (downdraft) gasifiers and the models reflect the state of the art achieved in coal gasification. On the contrary, only one highly simplified description has been proposed for the countercurrent (updraft) configuration, specifically applied for the gasification of bundled jute sticks (Kayal and Chakravarty, 1994).

In this study, a model is presented that is comprehensive of the main physical and chemical processes of countercurrent fixed-bed gasification of wood, a fuel whose behavior has not yet been simulated. Assumptions 1, 2, 3, 4, 7, and, in part, 9 (one-dimensional system; Hobbs et al., 1993) are still retained, but the model is dynamic, removes the other limitations, and takes into account the effects of axial heat conduction and mass diffusion. Also, simulations are carried out for a laboratoryscale plant (Di Blasi et al., 1999) and a comparison is provided between predictions and measurements.

\section{Problem Formulation}

A countercurrent gasification process (schematic in Figure 1) consists of a shaft continuously filled with wood chips, while air or a mixture of air and steam is injected from the bottom. Combustion takes place here, supplying heat for the globally endothermic processes of gasification, pyrolysis, drying, and, of course, for preheating the cold feed. These processes are stratified along the reactor height because wood particles encounter a gas at successively higher temperatures while descending toward the grate. However, this is only a rough schematization and, depending on feedstock characteristics and operating conditions, the different zones may overlap.

\section{Model equations for the fixed-bed reactor}

Countercurrent gasification processes are modeled by means of the equations of conservation of mass and energy for the solid and the gas phase on a macroscale, written for a onedimensional (reactor axis), unsteady system. No spatial intraparticle gradients of temperature exist, particles fed present the same size and (spherical) shape, and the porosity of the bed remains constant. As usually done in the mathematical modeling of fixed-bed reactors (Hobbs et al., 1993), turbulence is not formally considered in the formulation of the model equations, but is implicitly accounted for through the correlations for the heat/mass transfer coefficients. To reduce the number of input parameters needed for process simulation, the momentum balance is not considered. The model is thus applicable for quasiisobaric reactors (Buekens and Schoeters, 1985), that is, for reactors with a relatively shallow bed and high porosity. On the other hand, the pressure drop is expected not to be negligible in the presence of significant amounts of fines or when a thick layer of (fine) ash particles is built up to the grate.

The main processes modeled include:

(1) moisture evaporation/condensation;

(2) finite-rate kinetics of wood devolatilization and tar degradation;

(3) heterogeneous gasification (steam, carbon dioxide, and hydrogen) and combustion of char;

(4) combustion of volatile species;

(5) finite-rate gas-phase water-gas shift;

(6) extraparticle mass transfer resistances, through the introduction of apparent rates for the heterogeneous reactions according to the unreacted core model;

(7) heat and mass transfer across the bed resulting from macroscopic (convection) and molecular (diffusion and conduction) exchanges;

(8) absence of thermal equilibrium (different solid and gas temperatures);

(9) solid- and gas-phase heat transfer with the reactor walls;

(10) radiative heat transfer through the porous bed; and

(11) variable solid and gas flow rates.

The conservation equations are written for wood (1), moisture (2), gas-phase species (3-10) (oxygen, hydrogen, carbon monoxide, carbon dioxide, methane, steam, tar and nitrogen), total gas continuity (11), solid-phase enthalpy (12), and gasphase enthalpy (13), together with the ideal gas law (14):

Wood

$$
\frac{\partial \rho_{W}}{\partial t}+\frac{\partial U_{s} \rho_{W}}{\partial z}=-r_{p 1}
$$

Moisture

$$
\frac{\partial \rho_{M}}{\partial t}+\frac{\partial U_{s} \rho_{M}}{\partial z}=-m_{M}
$$

Gas-Phase Species

$$
\begin{gathered}
\varepsilon \frac{\partial \rho_{i}}{\partial t}+\frac{\partial\left(\rho_{i} U_{g}\right)}{\partial z}=\frac{\partial}{\partial z}\left(\varepsilon D_{i} \rho_{g} \frac{\partial Y_{i}}{\partial z}\right)+M_{i} \sum_{j} \nu_{i j} r_{j}+\nu_{i} r_{p 1} \\
i=\mathrm{O}_{2}, \mathrm{H}_{2}, \mathrm{CO}, \mathrm{CO}_{2}, \mathrm{CH}_{4} \quad j=c 1-c 5, g 1-g 3, w g
\end{gathered}
$$




\section{Steam}

$\varepsilon \frac{\partial \rho_{\mathrm{H} 2 \mathrm{O}}}{\partial \mathrm{t}}+\frac{\partial\left(\rho_{\mathrm{H} 2 \mathrm{O}} U_{g}\right)}{\partial z}=M_{\mathrm{H} 2 \mathrm{O}} \sum_{j} \nu_{\mathrm{H} 2 \mathrm{O} j} r_{j}$

$$
\begin{aligned}
+\frac{\partial}{\partial z}\left(\varepsilon D_{v} \rho_{g} \frac{\partial Y_{\mathrm{H} 2 \mathrm{O}}}{\partial z}\right)+ & m_{M}+\nu_{\mathrm{H} 2 \mathrm{O}} r_{p 1} \\
& j=c 1-c 5, g 1-g 3, w g
\end{aligned}
$$

Vapor-Phase Tar

$$
\varepsilon \frac{\partial \rho_{T}}{\partial t}+\frac{\partial\left(\rho_{T} U_{g}\right)}{\partial z}=\frac{\partial}{\partial z}\left(\varepsilon D_{T} \frac{\partial \rho_{T}}{\partial z}\right)+\nu_{T} r_{p 1}-r_{p 2}-r_{c 1}
$$

Nitrogen

$$
\rho_{\mathrm{N} 2}=\rho_{g}-\sum_{i \neq \mathrm{N} 2} \rho_{i}
$$

\section{Total Gas Continuity}

$$
\begin{array}{r}
\epsilon \frac{\partial \rho_{g}}{\partial t}+\frac{\partial\left(\rho_{g} U_{g}\right)}{\partial z}=\sum_{i} \sum_{j} \nu_{i j} M_{i} r_{j}+m_{M}+\left(1-\nu_{C}\right) r_{p 1} \\
i=\mathrm{N}_{2}, \mathrm{O}_{2}, \mathrm{H}_{2}, \mathrm{CO}, \mathrm{CO}_{2}, \mathrm{CH}_{4}, \mathrm{H}_{2} \mathrm{O} \\
j=c 1-c 5, g 1-g 3, w g
\end{array}
$$

\section{Solid-Phase Enthalpy}

$$
\begin{array}{r}
\frac{\partial\left(\sum_{i} \rho_{i} H_{s i}\right)}{\partial t}=\frac{\partial}{\partial z}\left(\lambda_{s}^{*} \frac{\partial T_{s}}{\partial z}\right)+\frac{\partial\left(U_{s} \sum_{i} \rho_{i} H_{s i}\right)}{\partial z}-\sum_{j} r_{j} \Delta H_{j} \\
-Q_{s g}+Q_{s w}-m_{M} \Lambda
\end{array}
$$

$H_{s i}=c_{s i}\left(T_{s}-T_{0}\right) \quad i=W, C, M \quad j=c 5, g 1-g 3, p 1$

\section{Gas-Phase Enthalpy}

$$
\begin{aligned}
\varepsilon \frac{\partial\left(\sum_{i} \rho_{i} H_{g i}\right)}{\partial t}=\frac{\partial}{\partial z}\left(\lambda_{g}^{*} \frac{\partial T_{g}}{\partial z}\right) & -\frac{\partial\left(U_{g} \sum_{i} \rho_{i} H_{g i}\right)}{\partial z} \\
& +Q_{s g}+Q_{g w}-\sum_{j} r_{j} \Delta H_{j}
\end{aligned}
$$

$$
\begin{gathered}
H_{g i}=c_{g i}\left(T_{g}-T_{0}\right) \\
i=\mathrm{N}_{2}, \mathrm{O}_{2}, \mathrm{H}_{2}, \mathrm{CO}, \mathrm{CO}_{2}, \mathrm{CH}_{4}, \mathrm{H}_{2} \mathrm{O}, T \\
j=c 1-c 4, w g, p 2 \\
Q_{s g}=h_{s g} A_{p} \nu_{p}\left(T_{s}-T_{g}\right) \\
Q_{s w}=\frac{4 h_{s w}}{D}\left(T_{w}-T_{s}\right)
\end{gathered}
$$

$$
Q_{g w}=\frac{4 h_{g w}}{D}\left(T_{w}-T_{g}\right)
$$

Ideal Gas Law

$$
P_{0}=\frac{\rho_{g} \Re T_{g}}{M_{g}}
$$

$$
M_{g}=\sum_{i} M_{i} Y_{i} \quad i=\mathrm{N}_{2}, \mathrm{O}_{2}, \mathrm{H}_{2}, \mathrm{CO}, \mathrm{CO}_{2}, \mathrm{CH}_{4}, \mathrm{H}_{2} \mathrm{O}, T
$$

The submodels for the source terms (chemical reactions and moisture evaporation), heat/mass transfer coefficients, and proper equations for the char density and the solid velocity are specified below.

\section{Moisture evaporation}

As in previous studies (Hobbs et al., 1993), moisture evaporation is diffusion controlled:

$$
\begin{aligned}
& m_{M}=\nu_{p} A_{p} k_{m}\left(\rho_{v}-\rho_{\mathrm{H} 2 \mathrm{O}}\right) \\
& \frac{\rho_{v} \Re T^{*}}{M_{v}}=\exp \left(a_{1}-\frac{a_{2}}{T^{*}}\right)
\end{aligned}
$$

where $T^{*}$ is the average value between the solid and the gas temperatures (Winslow, 1976).

\section{Pyrolysis kinetics}

A one-step global reaction is considered for wood devolatilization, where the fractions of gas, tar, and char (Antal, 1982, 1985a; Di Blasi, 1993) produced should be assigned

$$
\begin{aligned}
W \stackrel{k_{p 1}}{\longrightarrow} \nu_{\mathrm{C}} \mathrm{CHAR}+\nu_{\mathrm{CO}} \mathrm{CO}+\nu_{\mathrm{CO} 2} & \mathrm{CO}_{2}+\nu_{\mathrm{H} 2} \mathrm{H}_{2}+\nu_{\mathrm{CH} 4} \mathrm{CH}_{4} \\
& +\nu_{\mathrm{H} 2 \mathrm{O}} \mathrm{H}_{2} \mathrm{O}+\nu_{T} \mathrm{TAR} \quad(p 1)
\end{aligned}
$$$$
r_{p 1}=A_{p 1} \exp \left(-\frac{E_{p 1}}{\mathfrak{R} T_{s}}\right) \rho_{W}
$$

Tars undergo secondary cracking in the void spaces of the bed (one-step global reaction with Arrhenius rate), to produce secondary gases, whose composition should again be assigned

$$
\begin{gathered}
\mathrm{TAR} \stackrel{k_{p 2}}{\longrightarrow} \nu_{\mathrm{CO}}^{*} \mathrm{CO}+\nu_{\mathrm{CO} 2}^{*} \mathrm{CO}_{2}+\nu_{\mathrm{CH} 4}^{*} \mathrm{CH}_{4} \\
r_{p 2}=\varepsilon A_{p 2} \exp \left(-\frac{E_{p 2}}{\Re T_{g}}\right) \rho_{T}
\end{gathered}
$$

Kinetic constants for primary pyrolysis are derived from Roberts and Clough (1963), whereas those for tar cracking are from Liden et al. (1988) (Table 1). The enthalpy variation resulting from wood devolatilization is assumed to be negligible because its effects are usually small (Di Blasi, 2002). 
Table 1. Kinetic Constants, Reaction Heats, Char Composition $(\alpha, \beta), \mathrm{CO} / \mathrm{CO}_{2}$ Ratio $(\gamma)$ for Reaction $c 5$, and Parameters $\zeta$ and $k_{m}^{*}$

\begin{tabular}{|c|c|c|}
\hline Parameter & Value & Reference \\
\hline$k_{p 1}$ & $1.516 \times 10^{3} \exp \left(-75549 / T_{s}\right) \mathrm{s}^{-1}$ & Roberts and Clough (1963) \\
\hline$k_{p 2}^{p 1}$ & $4.26 \times 10^{6} \exp \left(-12919 / T_{g}\right) \mathrm{s}^{-1}$ & Liden et al. (1986) \\
\hline$k_{g 1}^{p 2}$ & $=k_{g 3}=10^{7} \exp \left(-26095 / T_{s}\right) \mathrm{m} \mathrm{s}^{-1} \mathrm{~K}^{-1}$ & Goeneveld and van Swaaij (1980) \\
\hline$k_{g 2}^{g 1}$ & $10^{4} \mathrm{exp}\left(-26095 / T_{s}\right) \mathrm{m} \mathrm{s}^{-1} \mathrm{~K}^{-1}$ & Estimated as in Hobbs et al. (1993) \\
\hline$r_{j}^{g 2}$ & $\begin{array}{l}9.2 \times 10^{6} \exp \left(-9650 / T_{g}\right) T_{g} C_{i} C_{\mathrm{O} 2} \mathrm{kmol} \mathrm{m}^{-3} \mathrm{~s}^{-1} \\
j=c 1, c 2, i=T, \mathrm{CH}_{4}\end{array}$ & Bryden and Ragland (1996) \\
\hline$r_{c 3}$ & $1.3 \times 10^{11} \exp \left(-15105 / T_{g}\right) C_{\mathrm{CO}} C_{\mathrm{O} 2} C_{\mathrm{H}_{2} \mathrm{O}}^{0.5} \mathrm{kmol} \mathrm{m}^{-3} \mathrm{~s}^{-1}$ & Cooper and Hallet (2000) \\
\hline$r_{c 4}$ & $10^{11} \exp \left(-10000 / T_{\mathrm{g}}\right) C_{\mathrm{H} 2} C_{\mathrm{O} 2} \mathrm{kmol} \mathrm{m}^{-3} \mathrm{~s}^{-1}$ & Di Blasi (2000) \\
\hline$k_{c 5}^{c 4}$ & $5.67 \times 10^{7} \exp \left(-19294 / T_{s}\right) \mathrm{m} \mathrm{s}^{-1} \mathrm{~K}^{-1}$ & Kashiwagi and Nambu (1992) \\
\hline$k_{E}$ & $0.0265 \exp \left(3966 / T_{s}\right)$ & Yoon et al. (1978) \\
\hline$k_{w g}^{L}$ & $2.78 \exp \left(-1513 / T_{g}\right) \mathrm{m}^{3} \mathrm{~s}^{-1} \mathrm{~mol}^{-1}$ & Biba et al. (1978) \\
\hline$\Delta h_{w o}$ & $41.2 \mathrm{~kJ} / \mathrm{mol}$ & Buekens and Schoeters (1985) \\
\hline$\Delta h_{c 5}$ & {$\left[0.5 \times 393.8\left(\mathrm{CO}_{2}\right)+0.5 \times 110.6(\mathrm{CO})\right] \mathrm{kJ} / \mathrm{mol}$} & Buekens and Schoeters (1985) \\
\hline$\vec{\Delta} h_{g 1}^{c s}$ & $-172.6 \mathrm{~kJ} / \mathrm{mol}$ & Buekens and Schoeters (1985) \\
\hline$\Delta h_{g 2}^{g 1}$ & $74.93 \mathrm{~kJ} / \mathrm{mol}$ & Buekens and Schoeters (1985) \\
\hline$\Delta h_{o 3}^{g 2}$ & $-131.4 \mathrm{~kJ} / \mathrm{mol}$ & Buekens and Schoeters (1985) \\
\hline$\Delta h_{c 1}^{8 j}$ & $-17473 \mathrm{~kJ} / \mathrm{kg}$ & Bryden and Ragland (1996) \\
\hline$\vec{\Delta} h_{c 2}$ & $-17473 \mathrm{~kJ} / \mathrm{kg}$ & Bryden and Ragland (1996) \\
\hline$\Delta h_{c 3}$ & $-10107 \mathrm{~kJ} / \mathrm{kg}$ & Bryden and Ragland (1996) \\
\hline$\Delta h_{c 4}^{c 3}$ & $-142919 \mathrm{~kJ} / \mathrm{kg}$ & Bryden and Ragland (1996) \\
\hline$\alpha$ & 0.2526 (estimated) & \\
\hline$\beta$ & 0.0237 (estimated) & \\
\hline$\gamma$ & 0.8013 & Yoon et al. (1984) \\
\hline$\zeta$ & 0.2 (estimated) & \\
\hline$k_{m}^{*}$ & $0.15 \mathrm{~m} / \mathrm{s}$ (estimated) & \\
\hline
\end{tabular}

It should be noted that the treatment of the pyrolysis kinetics used here is highly simplified and that more comprehensive mechanisms are currently available (see, for example, Antal, 1983, 1985a,b; Di Blasi, 2002; Di Blasi and Branca, 2001a). Moreover, as in all the previous models of fixed-bed countercurrent gasification, tar condensation and the possible changes induced by this process on the physical properties of the bed are not taken into account. From the practical side, although condensation in the upper part of the bed is observed to a certain extent (Di Blasi et al., 1999), temperatures are usually relatively high and most of the tars in the exit stream are in the vapor phase.

\section{Combustion and gasification kinetics}

Combustion of volatile products includes the reactions for tar [modeled as hydrocarbon $\mathrm{CH}_{1.522} \mathrm{O}_{0.0228}$ (Bryden and Ragland, 1996), with molecular weight of 94 (Corella et al., 1991)], methane, carbon monoxide, and hydrogen (Table 1)

$$
\begin{gathered}
\text { (tar) } \mathrm{CH}_{1.522} \mathrm{O}_{0.0228}+0.867 \mathrm{O}_{2} \stackrel{k_{c 1}}{\longrightarrow} \mathrm{CO}+0.76 \\
\mathrm{CH}_{4}+1.5 \mathrm{O}_{2} \stackrel{k_{c 2}}{\longrightarrow} \mathrm{CO}+2 \mathrm{H}_{2} \mathrm{O} \\
2 \mathrm{CO}+\mathrm{O}_{2} \stackrel{k_{c 3}}{\longrightarrow} 2 \mathrm{CO}_{2} \\
2 \mathrm{H}_{2}+\mathrm{O}_{2} \stackrel{k_{c 4}}{\longrightarrow} 2 \mathrm{H}_{2} \mathrm{O}
\end{gathered}
$$

The reaction rates are modeled as in Bryden and Ragland (1996), except that, for computational simplicity (Di Blasi,
2000), they are first-order with respect to fuel $(c 1, c 2)$ and oxygen $(c 3)$

$$
\begin{gathered}
r_{j}=\varepsilon A_{j} \exp \left(-\frac{E_{j}}{\Re T_{g}}\right) T_{g} C_{i} C_{\mathrm{O} 2} \quad j=c 1, c 2 \quad i=T, \mathrm{CH}_{4} \\
r_{c 3}=\varepsilon A_{c 3} \exp \left(-\frac{E_{c 3}}{\Re T_{g}}\right) C_{\mathrm{CO}} C_{\mathrm{O} 2} C_{\mathrm{H} 2 \mathrm{O}}^{0.5} \\
r_{c 4}=\varepsilon A_{c 4} \exp \left(-\frac{E_{c 4}}{\Re T_{g}}\right) C_{\mathrm{H} 2} C_{\mathrm{O} 2}
\end{gathered}
$$

The corresponding kinetic constants are derived from Bryden and Ragland (1996) (c1, c2), Cooper and Hallett (2000) (c3), and Di Blasi (2000) (c4). Heats of reaction for $c 1-c 4$ are those reported by Bryden and Ragland (1996).

The water-gas shift reaction (Table 1)

$$
\begin{gathered}
\mathrm{CO}+\mathrm{H}_{2} \mathrm{O} \stackrel{k_{w g}}{\rightleftharpoons} \mathrm{CO}_{2}+\mathrm{H}_{2} \\
r_{w g}=\varepsilon k_{w g}\left(C_{\mathrm{CO}} C_{\mathrm{H} 2 \mathrm{O}}-\frac{C_{\mathrm{CO} 2} C_{\mathrm{H} 2}}{K_{E}}\right) \\
k_{w g}=A_{w g} \exp \left(-\frac{E_{w g}}{\Re T_{g}}\right) \\
K_{E}=A_{E} \exp \left(\frac{E_{E}}{\Re T_{g}}\right)
\end{gathered}
$$


is also considered with finite-rate kinetics (Biba et al., 1978; the equilibrium constant is derived from Yoon et al., 1978) and reaction heat as in Buekens and Schoeters (1985).

Heterogeneous reactions of char are

$$
\begin{aligned}
\mathrm{CH}_{\alpha} \mathrm{O}_{\beta}+\gamma \mathrm{O}_{2} \stackrel{k_{c 5}}{\longrightarrow}\left(2-2 \gamma-\beta+\frac{\alpha}{2}\right) \mathrm{CO} \\
+\left(2 \gamma+\beta-\frac{\alpha}{2}+1\right) \mathrm{CO}_{2}+\frac{\alpha}{2} \mathrm{H}_{2} \mathrm{O} \\
\mathrm{CH}_{\alpha} \mathrm{O}_{\beta}+\mathrm{CO}_{2} \stackrel{k_{g 1}}{\longrightarrow} 2 \mathrm{CO}+\beta \mathrm{H}_{2} \mathrm{O}+\left(\frac{\alpha}{2}-\beta\right) \mathrm{H}_{2} \\
\mathrm{CH}_{\alpha} \mathrm{O}_{\beta}+\left(2-\frac{\alpha}{2}+\beta\right) \mathrm{H}_{2} \stackrel{k_{g 2}}{\longrightarrow} \mathrm{CH}_{4}+\beta \mathrm{H}_{2} \mathrm{O} \\
\mathrm{CH}_{\alpha} \mathrm{O}_{\beta}+(1-\beta) \mathrm{H}_{2} \mathrm{O} \stackrel{k_{g 3}}{\longrightarrow} \mathrm{CO}+\left(1-\beta+\frac{\alpha}{2}\right) \mathrm{H}_{2}
\end{aligned}
$$

In the char/oxygen reaction, the molar ratio of $\mathrm{CO}$ to $\mathrm{CO}_{2}$ produced is reported to be a function of the temperature (Cho and Joseph, 1981; Hobbs et al., 1993). As a reference value, a $1 / 1$ ratio is always chosen (Yoon et al., 1984), with the elemental composition of char consisting of $95 \% \mathrm{C}, 2 \% \mathrm{H}$, and $3 \% \mathrm{O}(\alpha=0.2526, \beta=0.0237$, and $\gamma=0.8013$, Table 1$)$.

The selection of the intrinsic kinetic constants is critical because the interpretation of the experimental data is generally based on a power-law dependency of both species concentrations involved in the reactions (char and oxidant/gasifying agent), which is not applicable in the unreacted-core model usually used for describing single-particle effects. Thus, the parameter values derived from Kashiwagi and Nambu (1992) for combustion and from Groeneveld and van Swaaij (1980) for gasification through carbon dioxide and steam are only the best guess from the literature (Table 1). The rate of hydrogen gasification is assumed to be 3 orders of magnitude slower (Hobbs et al., 1992). The enthalpy variation for the gasification reactions $g 1-g 3$ is derived from Kayal et al. (1994), whereas the corresponding values for char combustion are derived from Buekens and Schoeters (1985) for CO formation and again from Kayal et al. (1994) for $\mathrm{CO}_{2}$ formation (Table 1).

\section{Single-particle effects}

The assumption of isothermal particles leads to a devolatilization process controlled by either chemical reaction kinetics or external heat transfer (gas to solid heat transfer coefficient). Moreover, the rate constants (Roberts and Clough, 1963) used here can be considered representative of apparent kinetics (Di Blasi and Branca, 2001a), so that internal heat transfer resistances are also accounted for, although with a high simplification.

Previous literature (for example, Hobbs et al., 1993; Yoon et al., 1976) describes mass transfer limitations during the occurrence of heterogeneous reactions by means of the unreactedcore model with either constant or shrinking particle size, depending on the ash content of the fuel. The ash content of wood is small, so that the second approach is considered here.
To account for the simultaneous effects of the different resistances (diffusion through the gas film, surrounding the particle, and intrinsic chemical kinetics), an effective reaction rate is introduced, assuming a linear dependency on the oxidizing/ gasifying species concentration. The shrinkage occurs as a consequence of the heterogeneous reactions, whereas devolatilization and moisture evaporation cause a decrease in the bed density. Hence, the following equations (the reaction rates $r_{j}$ are per unit char mole consumed) are considered

$$
\begin{aligned}
& r_{j}=\frac{C_{i}}{\frac{1}{k_{m}}+\frac{1}{k_{j}}} A_{p} \nu_{p} \\
& k_{j}=A_{j} \exp \left(-\frac{E_{j}}{\mathfrak{R} T_{s}}\right) \quad j=c_{5}, g 1-g 3 \\
& i=\mathrm{O}_{2}, \mathrm{CO}_{2}, \mathrm{H}_{2}, \mathrm{H}_{2} \mathrm{O} \\
& \nu_{p}=\frac{(1-\varepsilon)}{V_{p}} \\
& A_{p} \nu_{p}=\frac{6(1-\varepsilon)}{d_{p}} \\
& \frac{V_{p}}{V_{p 0}}=\frac{d_{p}^{3}}{d_{p 0}^{3}} \quad d_{p} \geq d_{p \min } \\
& \frac{\partial \rho_{C}}{\partial t}+U_{s 0} \frac{\partial \rho_{C}}{\partial z}=\nu_{C} r_{p 1} \\
& \rho_{C 0} \frac{\partial U_{s}}{\partial z}=-\sum_{j} M_{C} r_{j} \quad j=c_{5}, g 1-g 3 \\
& \frac{V_{p}}{V_{p 0}}=\frac{U_{s}}{U_{s 0}} \\
& \rho_{C 0}=\nu_{C} \rho_{B 0}
\end{aligned}
$$

It is worth noting that the solid velocity is constant along the devolatilization region (equal to $U_{s 0}$ ), so that the effects of chemical reactions appear as a variation in the bed density (the char density is evaluated from Eq. 31). On the other hand, the bed density is constant along the gasification/combustion region (equal to $\rho_{C 0}$ ), and the changes induced by chemical reactions are taken into account by a variable solid velocity (evaluated from Eq. 32). The minimum size of the particle (when complete conversion is attained and the reaction rates are set to zero) and, consequently, the maximum particle number density $\nu_{p}$ are assigned through the parameter $d_{\text {pmin }}$, which can be related to the initial ash content of the fuel (Hobbs et al., 1993).

\section{Properties of heat and mass transfer coefficients}

Literature correlations are used for the solid/gas heat-transfer and the mass-transfer coefficients (Gupta and Todos, 1963) 


$$
\begin{gathered}
h_{s g}=\zeta \frac{2.06 c_{g} \rho_{g} U_{g}}{\varepsilon} \operatorname{Re}^{-0.575} \operatorname{Pr}^{-(2 / 3)} \\
k_{m}=\frac{2.06 U_{g}}{\varepsilon} \operatorname{Re}^{-0.575} \mathrm{Sc}^{-(2 / 3)} \quad k_{m} \leq k_{m}^{*}
\end{gathered}
$$

A correction factor, $\zeta$ (Eq. 35), is introduced along the char zone to take into account unsteady heat transfer effects in reacting systems (Hobbs et al., 1993). Small values have been shown (Cho and Joseph, 1981; Radulovic et al., 1995) to produce temperature profiles in agreement with measurements. Thus a reference value equal to 0.2 (Table 1) is chosen in this study. Because of the different scales of the conversion units (in particular, there is large uncertainty for low Reynolds numbers) and again the changes introduced by chemical reactions, Eq. 36 for the mass-transfer coefficient may lead to unrealistic temperature values. Corrective factors, which limit the maximum $k_{m}^{*}$ (Bhattacharya et al., 1986; Di Blasi, 2000) or reduce $k_{m}$ for all conditions (Goldmann et al., 1985), have also been introduced. The first approach is chosen here with $k_{m}^{*}=$ $0.15 \mathrm{~m} / \mathrm{s}$ (Table 1) as a reference value.

Viscosity and thermal conductivity of the gas are derived from Purnomo et al. (1988)

$$
\lambda_{g}=4.8 \times 10^{-4} T_{g}^{6.717} \quad \mu=1.98 \times 10^{-5}\left(T_{g} / 300\right)^{2 / 3}
$$

The effective thermal conductivities are modeled as in Goldman et al. (1984)

$$
\begin{gathered}
\lambda_{g}^{*}=\varepsilon \lambda_{g} \\
\lambda_{s}^{*}=\varepsilon \lambda_{r g}+\varepsilon \frac{\lambda_{s}}{\left[\lambda_{s} /\left(d_{p} \lambda_{r s}\right)+1.43(1-1.2 \varepsilon)\right]} \\
\lambda_{r g}=4 \sigma 0.05 T_{g}^{3} \\
\lambda_{r s}=4 \sigma 0.85 T_{s}^{3} \\
\lambda_{s}=0.0013+0.05\left(T_{s} / 1000\right)+0.63\left(T_{s} / 1000\right)^{2}
\end{gathered}
$$

\section{Boundary conditions}

At the bottom of the reactor $(z=0)$, temperature, velocity, and densities of the inlet stream are assigned. Also, the solid is assumed to be at ambient temperature, as observed for both wood (Di Blasi et al., 1999) and coal (Goldman et al., 1984) at a laboratory scale

$$
\begin{gathered}
\rho_{i}=0 \quad i=\mathrm{CO}_{2}, \mathrm{CO}, \mathrm{H}_{2}, \mathrm{CH}_{4}, T \\
\rho_{i}=\rho_{g 0} Y_{i 0} \quad i=\mathrm{N}_{2}, \mathrm{O}_{2}, \mathrm{H}_{2} \mathrm{O} \\
U_{g}=U_{g 0} \\
T_{g}=T_{0}
\end{gathered}
$$

$$
T_{s}=T_{0}
$$

At the reactor top $(z=L)$, the feed conditions are assigned and a convective outflow condition (Cooper and Hallett, 2000) is used for enthalpy and gas-phase species

$$
\begin{gathered}
\rho_{B}=\rho_{B 0} \\
U_{s}=U_{s 0} \\
\rho_{M}=\rho_{B 0} Y_{L 0} \\
\rho_{C}=0 \\
T_{s}=T_{s 0} \\
\frac{\partial T_{g}}{\partial z}=\frac{\partial \rho_{i}}{\partial z}=0 \quad i=\mathrm{CO}_{2}, \mathrm{CO}, \mathrm{H}_{2}, \mathrm{CH}_{4}, \mathrm{O}_{2}, \mathrm{H}_{2} \mathrm{O}, T
\end{gathered}
$$

\section{Initial conditions}

Given the transient character of the model, ignition can be simulated. In this case, the initial conditions describe a gasifier filled with wood particles while hot air is injected from the bottom. This causes wood devolatilization and ignition. After a certain time, when the reaction zone becomes sufficiently large, the air temperature is brought to the ambient value and the simulation is carried out with a chosen set of parameters. To reduce the computational time, in the simulations discussed here, a steady-state scenario, corresponding to a reaction zone located near the bottom of the reactor, was chosen as the initial condition (time equal zero) in all cases.

\section{Numerical solution}

The numerical solution of the model equations is based on the operator splitting procedure (Di Blasi and Branca, 2001b) and finite-differences approximations. The reactor is divided into a set of elementary cylindrical cells, whose cross sections coincide with the reactor cross section, whereas the height can be variable. The grid is staggered, that is, the velocities are positioned at the boundaries and the other variables (temperatures, densities, and so on) at the center of each elementary volume. The solution procedure is divided into three stages, corresponding to chemical reaction processes, heat exchange (between phases and with the reactor wall), and transport phenomena. For each time step, in the first two stages, for each elementary volume of ordinary differential equations, the solution is calculated by means of a first-order implicit Euler method. In the third step the transport equations, after discretization with the hybrid scheme, are solved through a semiimplicit procedure (Di Blasi and Branca, 2001b); that is, each conservation equation is implicit in the corresponding variable being conserved, whereas the other variables are taken as the last available values. For all stages, the equations for the condensed-phase variables are solved first, followed by those of gaseous components and temperatures. 
Table 2. Bed Properties for Beech Wood Particles as Reported by Di Blasi et al. (1999) or Estimated (*)

$$
\begin{aligned}
& \rho_{W 0}=360 \mathrm{~kg} / \mathrm{m}^{3} \\
& \varepsilon=0.5 \\
& L=0.5 \mathrm{~m} \\
& D=0.1 \mathrm{~m} \\
& d_{p 0}=0.005 \mathrm{~m} \\
& Y_{L 0}=5 \%, \mathrm{db} \\
& T_{w}=T_{b}=T_{s 0}=T_{g 0}=300 \mathrm{~K} \\
& Y_{\mathrm{N} 20}=0.764, Y_{\mathrm{O} 20}=0.23, Y_{\mathrm{H} 2 \mathrm{OO}}=0.006 \\
& d_{p \min }=0.005 d_{p 0} \\
& h_{w}=1.256 \mathrm{~W} \mathrm{~m}^{-2} \mathrm{~K}^{-1}(*)
\end{aligned}
$$

\section{Results}

The model was used to simulate a laboratory-scale plant (Di Blasi et al., 1999), which is a cylindrical shaft with $0.50 \mathrm{~m}$ length and $0.10 \mathrm{~m}$ internal diameter. Input data are summarized in Tables 1-3. The kinetic constants, the reaction heats, the elemental composition of char, the $\mathrm{CO} / \mathrm{CO}_{2}$ ratio for the reaction c5, and the two parameters $\zeta$ and $k_{m}^{*}$ are listed in Table 1 (reference data). The bed properties for beech wood particles (Table 2, reference data) are those of the experiments (Di Blasi et al., 1999), where the parameter $d_{\text {pmin }}$ was evaluated for an ash content of beech wood equal to $0.05 \%$ (Di Blasi et al., 2001). Moreover, the bed to wall heat-transfer coefficient $\left(0.167 \mathrm{~kJ} / \mathrm{m}^{2} \mathrm{~s}^{-1} \mathrm{~K}^{-1}\right)$ is chosen so as to give good agreement between predictions and measurements for all the air-to-fuel weight ratios investigated (Di Blasi et al., 1999). The specific heat and diffusivities are taken constant and evaluated for a temperature of $1000 \mathrm{~K}$, whereas the specific heats of wood, char, and tar are derived from Di Blasi (2002) (these parameters are not listed in Table 2).

Operating conditions of the gasifier, stoichiometric coefficients, and gas composition of both primary and secondary degradation of wood are also selected in accordance with experimental conditions/results and are reported in Table 3. The gasification tests (Di Blasi et al., 1999) were carried out for a constant bed height, using the fuel feed rate $W_{f}$ as the manipulated variable, when the air flow rate $W_{a}$ was varied. In this way, associated with different $W_{a}$ values, the air-to-fuel weight ratio $R$ also varied. The values of $W_{f}$ varied over a range of $1.260-2.340 \mathrm{~kg} / \mathrm{h}$, corresponding to $R$ between 1.27 and 1.05 .

It is well known that the yields of the three classes of products (char, tar, and gas) generated from primary wood degradation (reaction p1) are dependent on the heating conditions (see, for example, Di Blasi et al., 2001; Scott et al., 1988). In particular, it was observed that, in the gasification tests, the reduction in the parameter $R$ gave rise to successively higher temperatures, enhancing the formation of volatile products at the expense of char during the devolatilization stage. Hence, the stoichiometric coefficient $\nu_{C}$ is estimated from the pyrolysis of packed beds of beech wood particles (Di Blasi et al., 1999) carried out for temperatures reproducing those of the gasification tests. For maximum (external) temperatures of 700-850 $\mathrm{K}, \nu_{C}$ ranges between 0.35 and 0.255 . Given that the corresponding variations in the gas yield are smaller, to limit the number of variable input parameters, the coefficient $\nu_{G}$ was taken constant (the gas composition has also been evaluated in accordance with the measurements for an external temperature of $800 \mathrm{~K}$ and is reported in Table 3 ). Only the parameter $\nu_{T}$ was adjusted to compensate for the variations in $\nu_{C}$. Moreover, the influences of the pyrolysis conditions on the elemental char composition (Table 1) are neglected. Because of the mild thermal conditions of updraft gasification, the activity of reaction p2 (secondary tar degradation in the void fraction of the bed) is small. Therefore the corresponding composition of the gas (Table 3) was taken constant and estimated in accordance with Boroson et al. (1989).

To compare predictions and measurements, simulations were made for the four tests, indicated in Table 3 as a-d. The same input data (Tables 1-2) were used in all cases, except for the stoichiometric coefficients of the pyrolysis reaction $\mathrm{p} 1$. Moreover, to gain a better understanding of the process, a parametric analysis was carried out using case $\mathrm{c}$ as a reference. Simulations were made by varying separately either the air $\left(W_{a}\right)$ or the fuel $\left(W_{f}\right)$ feed rate, resulting in different values of $R$, the coefficient $\nu_{C}$ (char yield from the devolatilization reaction), and the reactor throughput (simultaneous variation in $W_{a}$ and $W_{f}$, keeping $R$ constant). Finally, the empirical parameter $\zeta$ was also varied in a relatively narrow range around the reference value (Table 1).

All the simulations were made with a time step of $10^{-3} \mathrm{~s}$ and space steps of $0.2 \mathrm{~cm}$, giving grid-independent solutions for the reference values of the input parameters (Tables 1-3).

\section{Structure of the reaction fronts}

The main features of the updraft gasification process are shown in Figures 2-5, which report the axial profiles of solid and gas temperatures, molar fractions of gas-phase species, reaction rates, gas and solid velocities, solid density $\left(\rho_{s}=\rho_{W}\right.$ $\left.+\rho_{C}\right)$, and particle volume for the case $\mathrm{c}(R=1.11)$ of Table 3 . The profiles shown here (and the followings unless otherwise specified) correspond to conditions of maximum solid temperature. In fact, limited to a thin zone (about $1.5 \mathrm{~cm}$ wide) above the grid, oscillatory phenomena were observed, whose nature and evolution is discussed in detail in the next section. As wood is fed at the gasifier top, evaporation of moisture occurs almost instantaneously, probably because of the highly simplified description of this process, resulting in a steep gradient in the total solid density and temperature, as previ-

Table 3. Air Feed Rate $\left(W_{a}\right)$, Fuel Feed Rate $\left(W_{f}\right)$, and Airto-Wood Ratio $(R)$ as in the Experimental Tests (Di Blasi et al., 1999) Indicated as (a)-(d), Stoichiometric Coefficients of Char and Tar for the Pyrolysis Reaction 1 (Di Blasi et al., 1999), and Composition of Gas Produced by Reactions $p 1$ (Di Blasi et al., 1999) and $p 2$ (Boroson et al., 1989)

Operating conditions and stoichiometric coefficients of reaction $p 1$

(a) $W_{a}=1.590 \mathrm{~kg} / \mathrm{h}, \quad W_{f}=1.250 \mathrm{~kg} / \mathrm{h}, \quad R=1.27$, $\nu_{C}=0.350, \quad \nu_{T}=0.385$

(b) $W_{a}=1.760 \mathrm{~kg} / \mathrm{h}, \quad W_{f}=1.560 \mathrm{~kg} / \mathrm{h}, \quad R=1.13$, $\nu_{C}=0.315, \quad \nu_{T}=0.420$

(c) $W_{a}=2.160 \mathrm{~kg} / \mathrm{h}, \quad W_{f}=1.950 \mathrm{~kg} / \mathrm{h}, \quad R=1.11$, $\nu_{C}=0.285, \quad \nu_{T}=0.450$

(d) $W_{a}=2.460 \mathrm{~kg} / \mathrm{h}, \quad W_{f}=2.340 \mathrm{~kg} / \mathrm{h}, \quad R=1.05$ $\nu_{C}=0.255, \quad \nu_{T}=0.480$

Gas composition, reaction $p 1$

$\nu_{\mathrm{CO}}=0.045, \quad \nu_{\mathrm{CO} 2}=0.10 \quad \nu_{\mathrm{CH} 4}=0.003, \quad \nu_{\mathrm{H} 2}=0.002$, $\nu_{\mathrm{H} 2 \mathrm{O}}=0.115$

Gas composition, reaction $p 2$

$\nu_{\mathrm{CO}}^{*}=0.70, \quad \nu_{\mathrm{CO} 2}^{*}=0.18, \quad \nu_{\mathrm{CH} 4}^{*}=0.12$ 


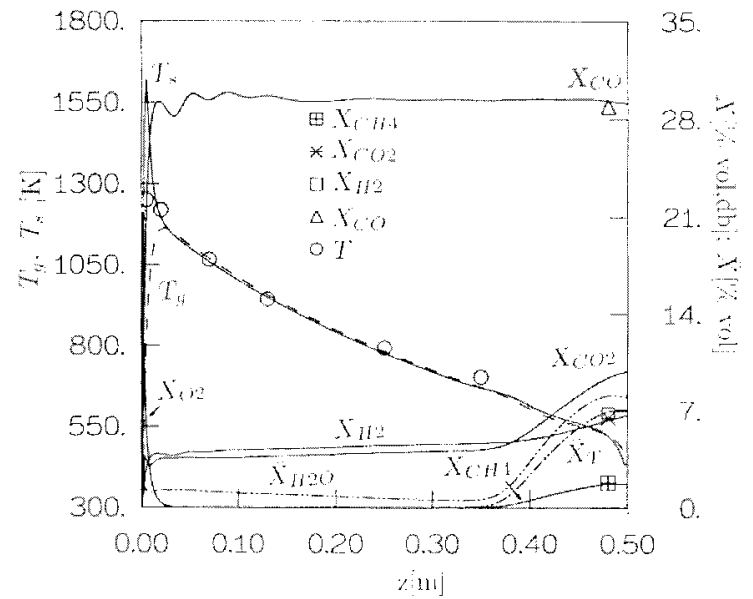

Figure 2. Axial profiles of solid and gas temperatures, molar fractions of $\mathrm{CO}, \mathrm{CO}_{2}, \mathrm{H}_{2}$, and $\mathrm{CH}_{4}$ (on dry basis), and $\mathrm{H}_{2} \mathrm{O}$ and tar (on total basis).

As predicted [reference data and case c $(R=1.11)$, lines] and measured (symbols; Di Blasi et al., 1999).

ously observed by Radulovic et al. (1995) for coal gasification. The gas temperature at the exit is about $420 \mathrm{~K}$.

Wood devolatilization, occurring at temperatures above 650 $\mathrm{K}$, is also characterized by significant spatial gradients $(z=$ $0.35 \mathrm{~m}$ ), again with a rapid change in the bed density (constant solid velocity) and temperature profiles (Figure 4). Because of devolatilization, tar vapors, steam, and gases are produced with a significant addition of mass to the gas phase. Secondary cracking reactions of tars do not occur because of the low temperatures in the upper part of the reactor (the maximum rate of reaction $\mathrm{p} 2$ is slower, by 3 orders of magnitude, than that of reaction p1; Figure 4). Consequently, as observed experimentally, the tar content of the gas is high ( $21 \%$ of the total molar concentration of gaseous effluents). Although the temperature is relatively low, the water gas shift reaction is active, given the high concentration of reactants (in particular steam). Apart

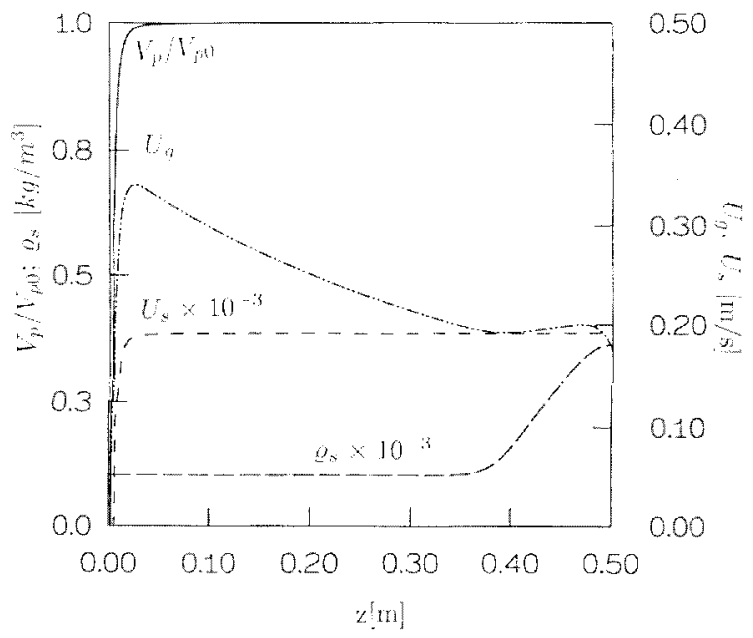

Figure 3. Axial profiles of solid and gas velocities, total density of the bed $\left(\rho_{s}=\rho_{w}+\rho_{C}\right)$, and particle volume.

As predicted with the reference data and case $\mathrm{c}(R=1.11)$.

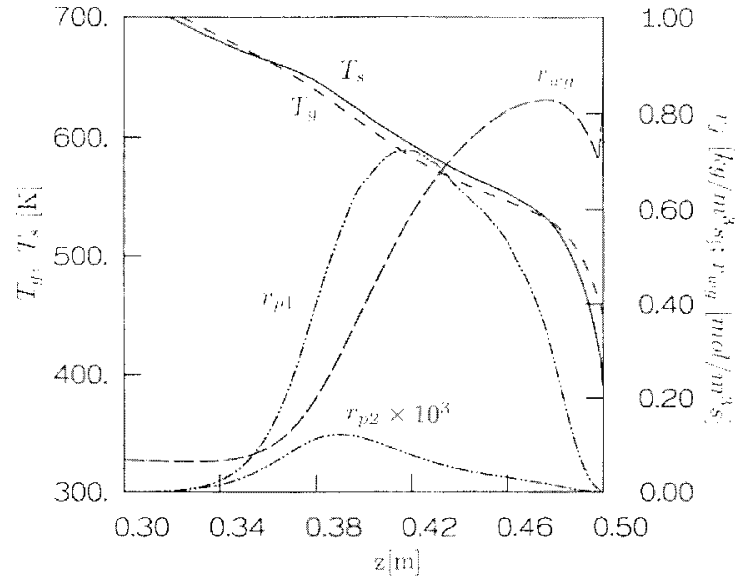

Figure 4. Axial profiles of temperatures, rates of primary and secondary pyrolysis reactions, and rate of the water-gas shift reaction along the drying/ devolatilization zone of the gasifier.

As predicted with the reference data and case $\mathrm{c}(R=1.11)$.

from $\mathrm{N}_{2}$, the most abundant among product species is $\mathrm{CO}$, followed by $\mathrm{CO}_{2}, \mathrm{H}_{2} \mathrm{O}, \mathrm{CH}_{4}$, and $\mathrm{H}_{2}$.

In the central zone of the gasifier the activity of both heterogeneous and homogeneous reactions is negligible, as indicated, on one side, by the constant value of bed density and solid velocity and, on the other side, by the absence of oxygen and tar. Gas-phase temperatures are slightly higher than those of the solid phase. Indeed, the main process occurring in this zone is the heating of the slowly descending char bed by means of the hot volatile products coming from the bottom. Again, this finding is in qualitative agreement with the literature on coal gasification (for example, Goldman et al., 1984).

Combustion and gasification are localized along a thin zone at the bottom of the gasifier, as shown by the profiles of the combustion/gasification rates (Figure 5). The rapid rise of the solid temperature up to values slightly below $1600 \mathrm{~K}$, just above the grate, is caused by char combustion, active for an

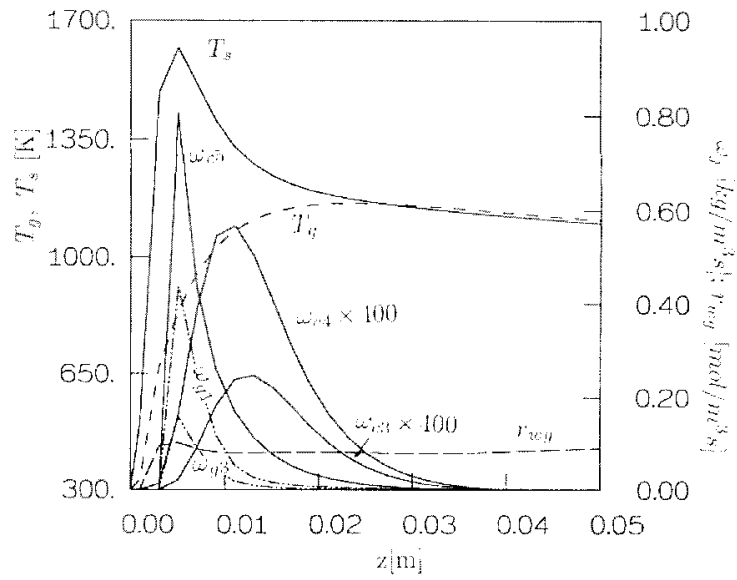

Figure 5. Axial profiles of temperatures and reaction rates along the combustion/gasification zone.

As predicted with the reference data and case $\mathrm{c}(R=1.11)$. The reaction rates $\left(\omega_{j}\right)$ refer to the grams of carbon $(g 1, g 3$, $c 5), \mathrm{CO}(c 4)$, or $\mathrm{H}_{2}(c 3)$ depleted. 
extension of about $2 \mathrm{~cm}$, corresponding to the 3-4 particle size previously reported (Goldman et al., 1984). As soon as the thermal conditions become severe and gasification starts, because of the high endothermicity, the solid-phase temperature undergoes a fast decrease, which quenches the heterogeneous reactions. In the bottom zone, the particle size and the solid velocity rapidly attain a minimum (Figure 3 ), whereas the particle density number attains a maximum. Also, gasification is responsible for the minimum in the $\mathrm{CO}_{2}$ and steam profiles (Figure 2).

As expected, the difference between the solid and gas temperatures is large at the grate, where air is fed at ambient conditions. Then, first because of heat transfer from solid to gas, the incoming gas is heated. The production of $\mathrm{CO}$ and $\mathrm{H}_{2}$ and the mixing with the residual air results in a premixed flame, which extends well above the gasification zone. However, because of the low gas-phase temperatures, the rates of the homogeneous combustion reactions are slower, by about 2 orders of magnitude, than those of the heterogeneous combustion/gasification reactions (Figure 5). At a distance of about 5 $\mathrm{cm}$ from the grate, the difference between the two temperatures becomes negligible. Over this distance combustion also terminates, as confirmed by the complete depletion of oxygen. Gasification/combustion of char and the rapid increase in temperature also cause high gas velocities. As noted by Hobbs et al. (1992) for fixed-bed coal gasification, the residence times of the gases in the reactor is a few seconds (about 1.5-2.5 s), whereas the residence time of the solid is longer by about 3 orders of magnitude.

Despite the combustion in the gas phase, $\mathrm{CO}$ rapidly attains the highest value, because it is a product of both $\mathrm{CO}_{2}$ and $\mathrm{H}_{2} \mathrm{O}$ gasification reactions. Hydrogen is essentially the product of steam gasification. However, the rate of char gasification through $\mathrm{H}_{2}$ appears to be very slow, so that the formation of $\mathrm{CH}_{4}$ is negligible.

Figure 2 shows that the temperature predictions are in good agreement with experimental measurements (Di Blasi et al., 1999), given that the measured values are essentially those of the solid particles (Di Blasi et al., 1999; Goldman et al., 1984). However, the few thermocouples positioned along the combustion/gasification zone, where the gradients are very high, do not allow confirmation of attaining the maximum given by the model. Also, sufficient detail is not available from the measurements for the drying/devolatilization regions. Indeed, because of tar vapor and steam condensation, frequent stirring of the upper part of the particle bed was required to avoid interruption of the gasification process (Di Blasi et al., 1999). The predictions of the producer gas are also in good agreement with the measurements, apart from slightly higher $\mathrm{CO}_{2}$ values. Given the highly simplified treatment of the devolatilization process, which contributes significantly in the gas composition, and the uncertainty about kinetic constants [in particular, catalytic effects of ashes (Yang et al., 1998) on the activity of the water gas shift reaction could be important] and heat/ mass transfer coefficients, this result can be considered good. Finally, the average conversion of wood to volatiles is about $95 \%$, a value also corresponding to that achieved in the experiments.

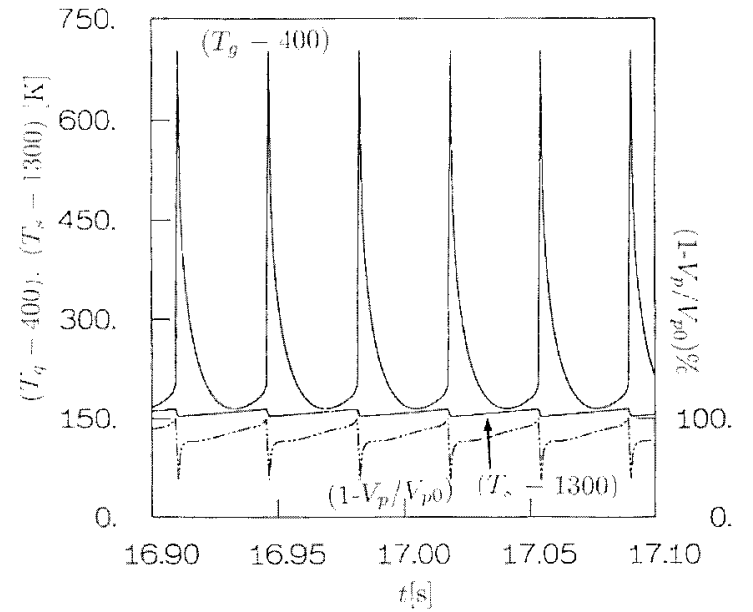

Figure 6. Time profiles of gas temperature, solid temperature, and conversion $\left[1-\left(V_{p} / V_{p 0}\right)\right]$ at $z=$ $0.1 \mathrm{~cm}$.

As predicted with the reference data, $\zeta=0.15$, and case $\mathrm{c}$ $(R=1.11)$.

\section{Dynamic patterns of the combustion/gasification zone}

As anticipated earlier, for the reference values of the input parameters, pulsating phenomena were simulated along a thin region at the bottom of the gasifier. From the analysis of the results it appears that they are caused by variations in the rates of solid/gas heat transfer, multiplied by the empirical parameter $\zeta$. Thus, to better understand the characteristics of the process, this was varied over a range from 0.13 to 0.26 , roughly corresponding to $\pm 25 \%$ the reference value. The input data and the feed conditions (case c) are those listed in Tables 1-3.

An example of the process dynamics at the bottom of the reactor $(z=0.1 \mathrm{~cm})$ is shown in Figure 6 (temperatures and conversion), as simulated for $\zeta=0.15$. The time profiles show a single periodic pulsating regime with a period of $36 \mathrm{~ms}$, where the amplitude of the oscillations is high for the gas-phase variables (temperature and concentrations of the gaseous species) and low for the solid-phase variables [temperature and conversion, $1-\left(V_{p} / V_{p 0}\right)$, which is directly related to the particle size (Eq. 30)]. The amplitude of the oscillations decreases as the distance from the grate increases and the maximum moves toward slightly longer times. They are limited to a region about $1.5 \mathrm{~cm}$ long, where high conversion (combustion and gasification) rates of the char, produced from the devolatilization process, are established.

The mechanism responsible for the pulsating regime is the heat transfer rate between solid and gas. Apart from the temperature difference and the parameter $\zeta$, this is proportional to the heat transfer coefficient $h_{s g}$, the particle density number $\nu_{p}$, and the particle surface $A_{p}$ (see Eq. 13c). Consequently, it is substantially affected by the particle size. In particular, it becomes progressively higher as the particle shrinks because of the increase of both $h_{s g}$ and the product $\nu_{p} A_{p}$ (see Eq. 29).

The sequence of events leading to an oscillating behavior can be summarized as follows. The solid-phase temperatures (and the heterogeneous reaction rates) attain a maximum when the particle size is at a minimum. Very fast rates of heat transfer from the solid to the gas phase are thus established, which 


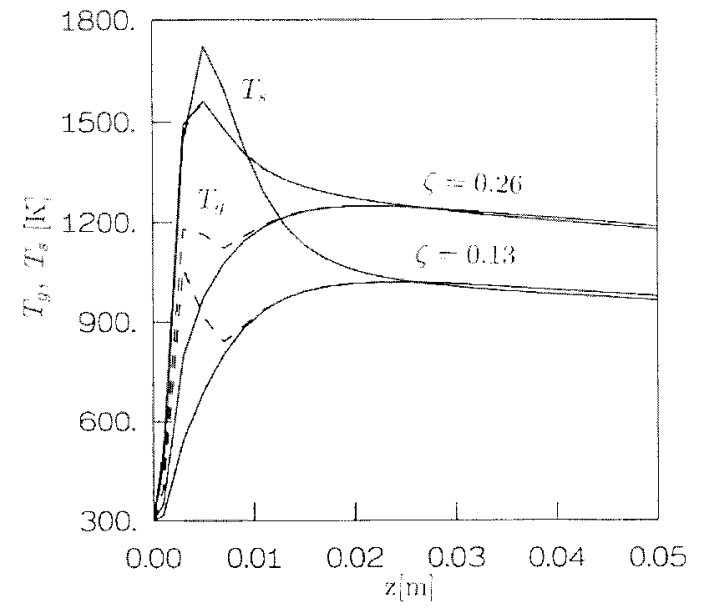

Figure 7. Axial profiles of solid and gas temperatures along the combustion/gasification zone.

As predicted for conditions of maximum solid temperature (solid lines) and maximum gas temperature (dashed lines) and two values of $\zeta(0.13$ and 0.26$)$ [reference data and case $c$ $(R=1.11)]$

eventually result in a maximum in the gas temperature (and a minimum in the solid temperature). Continuous operation, on the other hand, provides the discharge of ash (and low amounts of unburned char) and the appearance of unburned char at the bottom of the gasifier. In this way, the increased size of the particles causes a reduction in the rate of heat transfer from the solid to the gas phase, the gas-phase temperatures start to decrease and attain their minimum (conversely, the solid-phase temperatures start to increase and attain their maximum), and thus the cycle repeats again.

The controlling mechanisms and the sequence of events remain the same for $0.13 \leq \zeta \leq 0.26$, although with some modifications. From a qualitative perspective, single periodic pulsations are followed by more complex periodic behaviors for the gas-phase variables, which show two or three local maxima, and then by the absence of a rigorously periodic behavior. The duration of the cycle (or the characteristic times associated with the maximum solid conversion) increases with $\zeta$ (values in the range $25-100 \mathrm{~ms}$ ), owing to the decrease of the solid-phase temperature and consequently of the heterogeneous reaction rates. The maximum amplitude in the oscillations is always observed at the bottom of the reactor $(z=0.1 \mathrm{~cm})$ and it increases with $\zeta$ for both the solid and the gas temperatures (variation from about 10 to $20 \mathrm{~K}$ for the former and from about 530 to $720 \mathrm{~K}$ for the latter), whereas the extension of the spatial zone with respect to the fluctuations remains roughly the same.

The spatial temperature profiles, reported in Figure 7, for conditions of maximum solid temperature (solid lines) and maximum gas temperature (dashed lines) at $z=0.1 \mathrm{~cm}$ and two values of $\zeta(0.13$ and 0.26$)$ show that the spatial profiles are significantly affected by the rate of solid/gas heat transfer. In particular, the extension of the combustion/gasification zone becomes successively wider and the spatial gradients are reduced as $\zeta$ is increased. Finally, the average solid conversion (about $95 \%$ ) is not significantly affected.

The very few dynamic models of coal gasification have shown different types of responses and the existence of multiple steady states, although these phenomena are not supported by experimental evidence (Buekens and Schoeters, 1985). This model predicts that oscillations are limited to a very thin zone. For the reduced rates of solid/gas heat transfer (low $\zeta$ values), which are required for quantitative predictions, a very high frequency is established. In addition, the oscillations in the solid-phase temperature, which is the temperature actually measured, are small. The influences on the practical aspects of wood gasification, such as wood conversion and composition of the producer gas, are negligible. For these reasons, it could be difficult to detect such behavior experimentally. On the other hand, it cannot be excluded that the observed dynamic patterns are only a peculiarity of the mathematical model, in particular, the treatment applied to describe particle consumption.

\section{Effects of the air-to-wood/char weight ratio and reactor throughput}

Figure 8 shows that the temperature profiles simulated (input data as in Tables 1-3) for cases a-d and the values measured (steady conditions; Di Blasi et al., 1999) compare well. The molar composition of the producer gas measured at a laboratory scale is very close to that reported for industrial-scale plants (Buekens et al., 1990; Kurkela et al., 1989) and is weakly affected by the experimental range of $R$ values. The same trend is also predicted by the simulations that, given the uncertainty in the kinetic constants and heat/mass transfer coefficients, are also acceptable from a quantitative perspective. Indeed, the predicted (vs. measured) molar fractions (vol $\%, \mathrm{db}$ ) vary between 28 and 30 for $\mathrm{CO}(29-30), 9$ and 12 for $\mathrm{CO}_{2}(5.5-7), 6$ and 8 for $\mathrm{H}_{2}(6-7)$, and 1.8 and 2 for $\mathrm{CH}_{4}$ (1.6-2).

Temperature profiles and gas composition ensue from the combined effects of three parameters $\left(W_{f}, W_{a}\right.$, and $\left.\nu_{C}\right)$, which produce different air-to-fuel weight ratios and reactor throughputs. Thus, to better understand the process, an analysis was also carried out, in which the role of each parameter was separately investigated within roughly the experimental range of values (reference data and case c). In all cases, the process

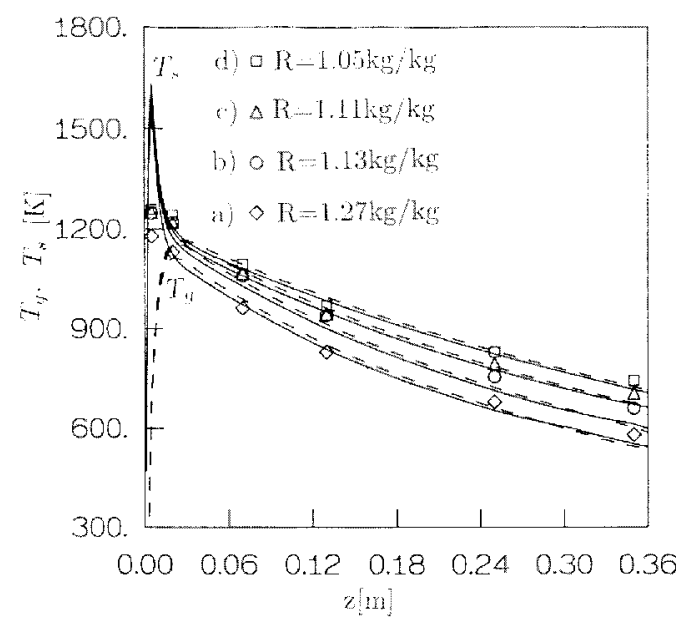

Figure 8. Axial profiles of solid and gas temperatures.

As predicted with the reference data and cases a-d (lines) and measured (symbols; Di Blasi et al., 1999). 


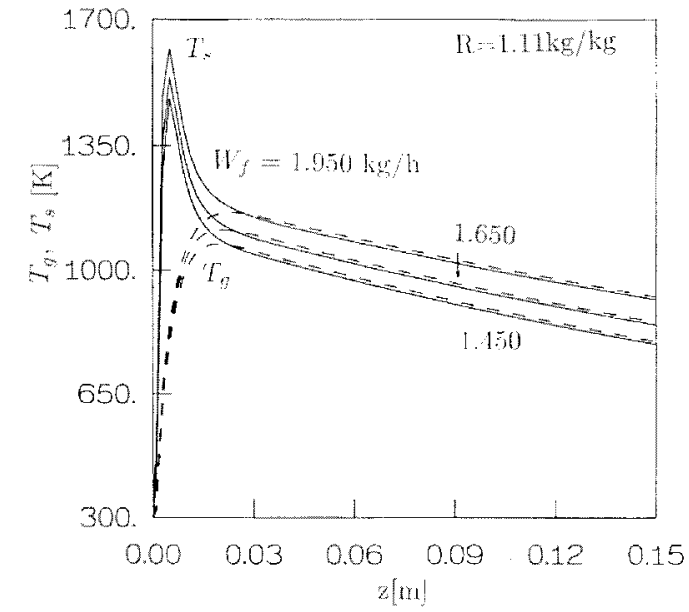

Figure 9. Axial profiles of solid and gas temperatures.

As predicted along the combustion/gasification zone for different reactor throughputs [reference data and case $\mathrm{c}(R=$ $1.11)]$.

dynamics and the structure of the reaction fronts remain the same as already discussed for case $\mathrm{c}$ in Figures 2-5.

Examples of temperature profiles simulated for different reactor throughputs, selected so as to give $R=1.11$, are shown in Figure 9. It can be seen that successively higher air and wood feed rates lead to higher temperatures along the entire bed length, although the shape of the profiles is not altered. Associated with the increased temperatures, higher $\mathrm{CO}$ (from 21 to $27 \mathrm{vol} \%, \mathrm{db}$ ) and lower $\mathrm{CO}_{2}$ (from 14 to $10 \mathrm{vol} \%, \mathrm{db}$ ) molar fractions are also simulated at the reactor exit. Given the constant values of the stoichiometric coefficients of the primary and secondary pyrolysis reactions, it can be understood that these results are attributed to an improved gasification efficiency. These findings are in agreement with previous literature (Bryden and Ragland, 1996; Kayal and Chakravarty, 1994).

Simulations were also carried out by varying separately the wood and the air flow rate, which produce variable air-to-wood weight ratios. Again, the reference values for the two parameters are those of case c (Table 3), whereas $W_{f}$ (with $W_{a}=$ $2.165 \mathrm{~kg} / \mathrm{h}$ ) or $W_{a}$ (with $W_{f}=1.950 \mathrm{~kg} / \mathrm{h}$ ) were varied, so as to obtain $R$ values between 1.11 and 1.25. The small variations in the operating parameters result in a fixed position of the maximum solid temperature and a constant size of the combustion/ gasification zone. Quantitative differences are relatively small for both the gas composition and the maximum temperatures, as shown in Figure 10. Because of the constant extension of the reaction zone, successively higher values of $R$ are associated with an increased amount of air with respect to the amount of fuel. Thus, whereas the heat request for heating the air increases, the availability of fuel, to be burned for sustaining the endothermic gasification process and heat losses, diminishes. As an overall effect, the maximum temperatures slightly decrease. Moreover, the concentration of nitrogen at the reactor exit increases at the expense of those of combustible species. For instance, for $R$ in the range of values of Figure 10, the molar fraction of carbon monoxide decreases from about 30 to $26 \mathrm{vol} \%, \mathrm{db}$ (for nitrogen it increases from about 53 to $57 \mathrm{vol}$ $\%, \mathrm{db})$.

The narrow range of $R$ investigated represents near-limit conditions. Indeed, for values slightly above $1.3-1.4$, depending on reactor throughput, after some transients show a constant propagation rate of the combustion/gasification zone toward the top of the bed, eventually extinction takes place. This behavior is in qualitative agreement with results reported in previous studies (Goldman et al., 1984; Monazam and Shadle, 1998). The dependency of the composition of the producer gas on $R$ also agrees with previous literature (Hobbs et al., 1992; Kayal and Chakrawarty, 1994; Monazam and Shadle, 1998). More complicated is the comparison of the trends shown by the maximum solid temperature.

Experimental and theoretical results on the reverse combustion of small-scale static beds of wood particles (Fatehi and Kaviany, 1994; Shin and Choi, 2000) and the smoldering combustion of loosely packed beds (for example, Leach et al., 1998) indicate the existence of a regime of decreasing temperatures (and propagation speed of the combustion front) at near-extinction conditions. Similar to the problem examined here, this is attributed to convective cooling of the reaction front by an excess of air with respect to the heat released from combustion. On the other hand, unpublished results for a 300 $\mathrm{kg} / \mathrm{h}$ updraft wood gasifier, obtained with the model of this study, show a moderate increase of the maximum solid temperature with $R$. The same trend is also reported by the few simulations available for industrial countercurrent coal gasifiers (Hobbs et al., 1992; Monazam and Shadle, 1998). Furthermore, although the extinction modality is the same as that observed on a small scale, $R$ values up to about 4 are still applicable (see, for example, Hobbs et al., 1992). The apparent disagreement between small- and large-scale systems is justified by the different stability characteristics and thermal conditions of the combustion/gasification zone, not to mention the fuel properties (particle size, ash and volatile content, etc.) and reactor design.

In particular, for large-scale coal gasifiers (Hobbs et al., 1992 ), as $R$ is increased, the structure of the reaction fronts is modified: the maximum solid temperature is positioned at a

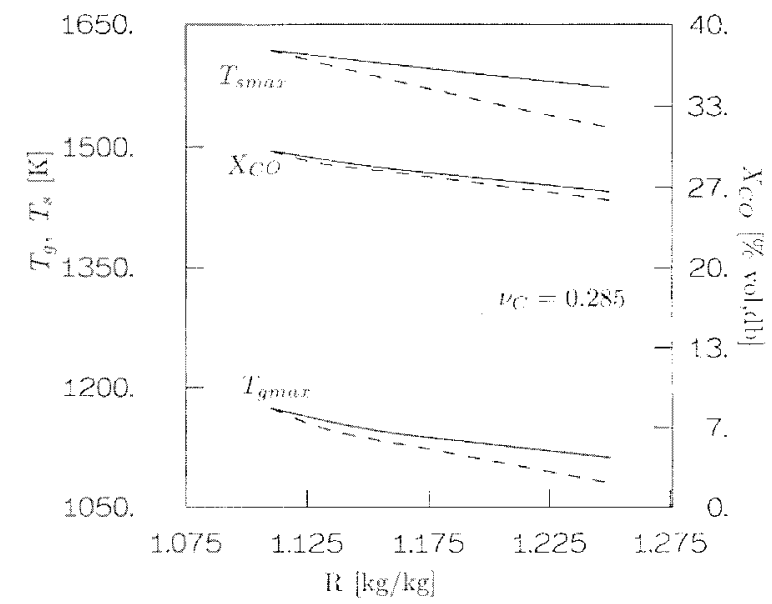

Figure 10. Maximum temperatures of the solid and the gas phase and molar fraction of $\mathrm{CO}$ at the gasifier exit.

As predicted by varying $W_{a}$ (solid lines) or $W_{f}$ (dashed lines) as functions of the air-to-fuel weight ratio (reference data and case c). 


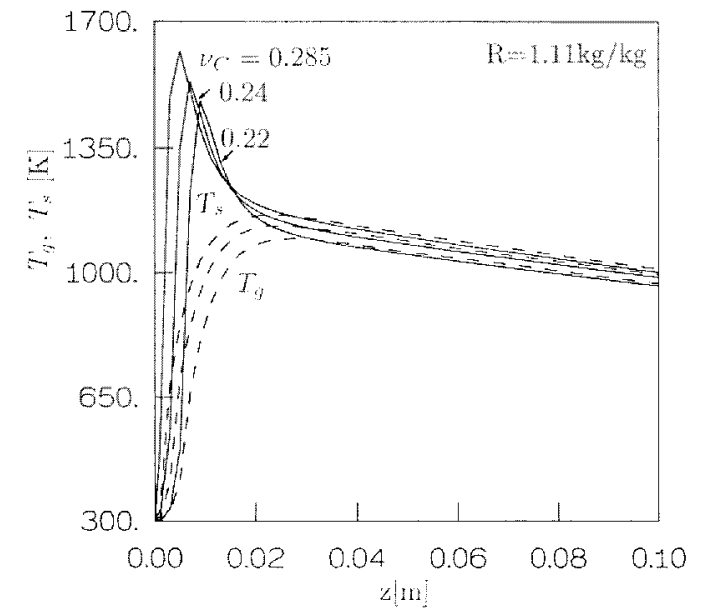

Figure 11. Maximum temperatures of the solid and gas phases and molar fraction of $\mathrm{CO}$ at the gasifier exit.

As predicted by varying the stoichiometric coefficient $\nu_{C}$ [reference data and case $\mathrm{c}(R=1.11)]$.

successively greater distance from the bottom where the spatial gradients also become lower. In other words, the higher air flow rates (or the reduced rate of fuel supply) are compensated by an increased extension of the preheating zone above the grate and the enhanced activity of combustion reactions results in higher solid temperatures. The better stability characteristics of large-scale systems at high $R$ values stem from a higher thermal efficiency. Indeed, it is well known that the ratio between the heat generated and the heat lost (from walls and grate) substantially increases concomitantly with the scale of the process. Moreover, the rate of solid to gas heat transfer also appears to be significantly higher for large-scale systems, given that only $\zeta$ values of $0.05-0.1$ (Hobbs et al., 1992) or 0.02 (Monazam and Shadle, 1998) can produce quantitative results (against the values of $0.2-0.22$ found here). This circumstance is also responsible for the much greater amount of heat generated from heterogeneous combustion being stored in the solid phase, thus favoring the temperature increase.

Consequent to the significant changes along the combustion/ gasification zone caused by variations in $R$, it can be expected that the rate of char supply plays a role as important as that of the wood feed rate. Thus simulations were also made for a constant $R$ (case c) by varying the stoichiometric coefficient $\nu_{C}$. For simplicity, observing that the composition of the pyrolysis gas does not affect the characteristics of the combustion gasification zone, only the coefficient $\nu_{T}$ was properly adjusted. Simulations confirm that the effects of a decrease in $\nu_{C}$ are qualitatively similar to those caused by increasing $R$ by means of successively lower $W_{f}$ values. Indeed, both the maximum temperatures (Figure 11) and the concentration of combustible gas at the reactor exit decrease [such as the $\mathrm{CO}$ molar fraction at the reactor exit from 29 to 23 vol $\%$ db (not shown)]. Furthermore, for $\nu_{C}<0.24$, the reaction front first stabilizes at increasing distances from the grate (see the position of the maximum temperatures in Figure 11) and then $\left(\nu_{C}=0.21\right)$ it is no longer stable and extinction occurs.

The parametric investigation about the effects of reactor throughput, air-to-wood feed ratio, or air-to-char (through the coefficient $\nu_{C}$ ) feed rate show that the axial profiles of temperatures and the composition of the producer gas are strictly related. In summary, an increase in the reactor throughput (and in the rate of char supply) always causes higher temperatures and a higher heating value of the producer gas. On the other hand, an increase in the air-to-wood weight ratio, for the small-scale system examined, always results in reduced temperatures and heating value of the producer gas.

In particular, with reference to the simulated and measured temperature profiles reported in Figure 8, it can be observed that the reduction in the yields of char generated from wood devolatilization is less important than the improvement in the gasification efficiency, associated with the simultaneous decrease in the air-to-wood weight ratio and increase in reactor throughput (higher temperatures). Thus, at low temperatures (high $R$ and low reactor throughput), the amount of char produced from wood devolatilization is high. However, the thermal conditions are hardly sufficient for char gasification. Therefore, only a small part of carbon dioxide, produced from char combustion, is actually consumed by char gasification. As the bed temperature increases (low $R$ and high reactor throughput), although the amount of char produced from wood pyrolysis slightly decreases (the yields of gas may also increase at a certain extent, although this is not accounted for in these simulations), the gasification process is improved because of both the more favorable thermal conditions and the larger amounts of carbon dioxide, produced from combustion, with an improvement in the heating value of the producer gas.

\section{Conclusions}

A mathematical model for the gasification of wood in a countercurrent fixed-bed reactor, comprehensive of the main chemical and physical processes, has been formulated and solved. The effort is particularly important because this topic was not addressed by previous studies. The number of input parameters is considerably high, however, because the majority of the values were derived from the literature. Simulations were made for a laboratory-scale system that, thanks to the availability of experimental measurements, was also useful for model validation.

Predictions show the existence of four main regions along the gasifier axis. In the first, gasification and combustion overlap, the second is essentially the inert heating of a descending bed of char particles, and the last two are associated with wood devolatilization and drying, respectively. This structure of the reaction fronts is qualitatively similar to that reported for coal gasification.

Axial profiles of temperature and composition of the producer gas are in good agreement with measurements carried out at a laboratory scale for air-to-fuel weight ratios in the range 1.05-1.27. Simulations were made with no adjustable parameter apart from the stoichiometry of the global reaction of primary wood degradation, which is known to be significantly dependent on the heating conditions. A parametric analysis verified that the gasification efficiency is favored by the higher temperatures caused by an increase in the reactor throughput. These positive effects are counteracted, to some extent, by the reduced rates of char supply to the combustion/gasification zone. Indeed, higher temperatures also favor devolatilization vs. charring reactions during wood pyrolysis. 
The unsteady character of the model allowed simulation of the oscillating phenomena localized along the thin combustion/ gasification zone. Oscillations on the process variables are caused by the periodic attainment of very high rates of solid consumption that, by a reduction in the particle size at the minimum value (along a very narrow zone, where the gas is still cold), give rise to a momentary rapid increase in the rate of heat transfer from the solid to the gas phase. In terms of global parameters (that is, overall wood conversion and composition of the producer gas), however, these effects are small.

Numerical simulations indicate that several processes, such as char gasification with $\mathrm{H}_{2}$, combustion of $\mathrm{CH}_{4}$, decomposition, and combustion of tar, are unimportant and can be deleted from the mathematical model.

There are numerous issues in the modeling of updraft wood gasification that should be addressed in future studies. Although the computer model presented here has proved capable of quantitative predictions of a laboratory-scale system, further validation is required for industrial-scale reactors that experience highly different thermal and stability conditions. An extensive sensitivity analysis to all the input parameters should also be carried out to evaluate the applicability of additional simplifications in the mathematical formulation of the problem and to determine the controlling variables with respect to reactor throughput and heating value of the producer gas. Similar to the analysis carried out by Monazam and Shadle (1998), extensive numerical simulations can also be applied to produce empirical correlations for the key parameters, as functions of operating conditions, to be used for design and scaling purposes.

\section{Notation}

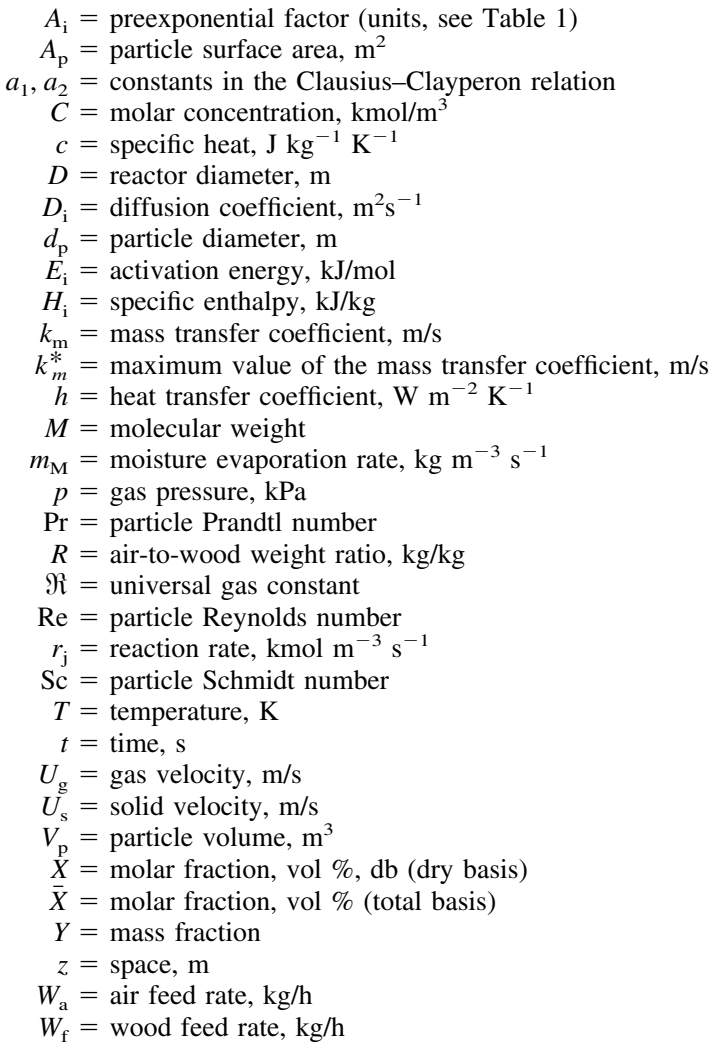

\section{Greek letters}

$\gamma=$ stoichiometric coefficient for reaction $c 5$

$\nu_{\mathrm{p}}=$ particle density number, $1 / \mathrm{m}$

$\nu=$ stoichiometric coefficient for reactions $p 1$ and $p 2$

$\rho_{\mathrm{W}, M}=$ apparent solid density (mass/total volume), $\mathrm{kg} / \mathrm{m}^{3}$

$\rho_{\mathrm{C}}=$ constant bed density in the combustion/gasification zone, $\mathrm{kg} / \mathrm{m}^{3}$

$\rho_{\mathrm{i}}=$ gas phase mass concentration (mass/gas volume), $\mathrm{kg} / \mathrm{m}^{3}$

$\varepsilon=$ porosity

$\Delta h=$ reaction enthalpy, $\mathrm{kJ} / \mathrm{kg}$

$\Lambda=$ moisture (evaporation) enthalpy, $\mathrm{kJ} / \mathrm{kg}$

$\lambda^{*}=$ thermal conductivity, $\mathrm{W} \mathrm{m} \mathrm{m}^{-1} \mathrm{~K}^{-1}$

$\mu=$ viscosity, $\mathrm{kg} / \mathrm{ms}$

$\omega_{\mathrm{j}}=$ combustion or gasification rate, $\mathrm{kg} \mathrm{m}^{-3} \mathrm{~s}^{-1}$

$\zeta=$ correction factor for the solid/gas heat transfer coefficient

\section{Subscripts}

$C=$ char

$c 1=$ tar combustion

$c 2=$ methane combustion

$c 3=$ carbon monoxide combustion

$c 4=$ hydrogen combustion

$c 5=$ char combustion

$\mathrm{CH} 4=$ methane

$\mathrm{CO}=$ carbon monoxide

$\mathrm{CO} 2=$ carbon dioxide

$E=$ equilibrium

$g=$ total volatiles (vapor + gas)

$g 1=$ carbon dioxide gasification

$g 2=$ hydrogen gasification

$g 3=$ steam gasification

$\mathrm{H} 2$ = hydrogen

$\mathrm{H} 2 \mathrm{O}=$ steam

$i=$ chemical species

$M=$ moisture

$\max =$ maximum

$\min =$ minimum

$\mathrm{O} 2=$ oxygen

$p 1=$ primary pyrolysis

$p 2=$ secondary pyrolysis

$s=$ solid (wood + char)

$T=\operatorname{tar}$

$v=$ vapor

$W=$ wood

$w g=$ water gas shift

$w=$ wall

$0=$ ambient or initial value

$\alpha=\mathrm{H}$ moles in char

$\beta=\mathrm{O}$ moles in char

\section{Acknowledgments}

The computer code was developed with the partial support of the European Commission in the framework of the Non Nuclear Energy Programme (JOULE III), Contract JOR3-CT95-0021.

\section{Literature Cited}

Antal, M. J., "Biomass Pyrolysis: A Review of the Literature. Part I. Carbohydrate Pyrolysis," Advances in Solar Energy, K. W. Boer and J. A. Duffie, eds., American Solar Energy, Boulder, CO, pp. 61-111 (1982).

Antal, M. J., "Effects of Reactor Severity on the Gas-Phase Pyrolysis of Cellulose- and Kraft Lignin-Derived Volatile Matter," Ind. Eng. Prod. Res. Dev., 22, 366 (1983).

Antal, M. J., "Biomass Pyrolysis: A Review of the Literature. Part II. Lignocellulose Pyrolysis," Advances in Solar Energy, K. W. Boer and J. A. Duffie, eds., Plenum Press, New York, Vol. 2, pp. 175-255 (1985a).

Antal, M. J., "A Review of the Vapor Phase Pyrolysis of Biomass Derived Volatile Matter," Fundamentals of Thermochemical Biomass Conversion, R. P. Overend, T. A. Milne, and L. K. Mudge, eds., Elsevier Applied Science, New York, pp. 511-537 (1985b). 
Beenackers, A. A. C. M., and K. Maniatis, "Gasification Technologies for Heat and Power from Biomass," Proc. of the 9th European Bioenergy Conference, P. Chartier, G. L. Ferrero, U. M. Henius, J. Huntberg, J. Sachau, and M. Wiinblad, eds., Pergamon Press, Oxford, UK, p. 228 (1996).

Bhattacharya, A., L. Salam, M. P. Dudukovic, and B. Joseph, "Experimental and Modeling Studies in Fixed-Bed Char Gasification," Ind. Eng. Chem. Process Des. Dev., 25, 988 (1986).

Biba, V., J. Macak, E. Klose, and J. Malecha, "Mathematical Model for the Gasification of Coal Under Pressure," Ind. Eng. Chem. Process Des. Dev., 17, 92 (1978).

Boroson, M. L., J. B. Howard, J. P. Longwell, and A. W. Peters, "Products Yields and Kinetics from the Vapor Phase Cracking of Wood Pyrolysis Tars," AIChE J., 35, 120 (1989).

Bryden, K. M., and K. Ragland, "Numerical Modeling of a Deep, FixedBed Combustor," Energy \& Fuels, 10, 269 (1996).

Buekens, A. G., A. V. Bridgwater, G. L. Ferrero, and K. Maniatis, "Commercial and Marketing Aspects of Gasifiers," Commission of the European Communities, EUR 12736, Brussels, Belgium (1990).

Buekens, A. G., and J. G. Schoeters, "Modeling of Biomass Gasification," Fundamentals of Thermochemical Biomass Conversion, R. P. Overend, T. A. Milne, and L. K. Mudge, eds., Elsevier, London, p. 619 (1985).

Cho, Y. S., and B. Joseph, "Heterogeneous Model for Moving-Bed Coal Gasification Reactors," Ind. Eng. Chem. Process Des. Dev., 20, 314 (1981).

Cooper, J., and W. L. Hallet, "A Numerical Model for Packed-Bed Combustion of Char Particles," Chem. Eng. Sci., 55, 4451 (2000).

Corella, J., M. P. Aznar, J. Delgado, and E. Aldea, "Steam Gasification of Cellulosic Wastes in a Fluidized Bed with Downstream Vessels," Ind. Eng. Chem. Res., 30, 2252 (1991).

Di Blasi, C., "Modeling and Simulation of Combustion Processes of Charring and Non-Charring Solid Fuels," Prog. Energy Combust. Sci., 19, 71 (1993).

Di Blasi, C., "Dynamic Behavior of Stratified Downdraft Gasifiers," Chem. Eng. Sci., 55, 2931 (2000).

Di Blasi, C., "Modelling Intra- and Extra-Particle Processes of Wood Fast Pyrolysis," AIChE J., 48, 2386 (2002).

Di Blasi, C., and C. Branca, "Kinetics of Primary Product Formation from Wood Pyrolysis," Ind. Eng. Chem. Res., 40, 5547 (2001a).

Di Blasi, C., and C. Branca, "A Mathematical Model for the Non-Steady Decomposition of Intumescent Coatings," AIChE J., 47, 2359 (2001b).

Di Blasi, C., C. Branca, A. Santoro, and E. Gonzalez Hernandez, "Pyrolytic Behaviour and Products of Some Wood Varieties," Combustion \& Flame, 124, 165 (2001).

Di Blasi, C., G. Signorelli, and G. Portoricco, "Fixed-Bed Countercurrent Gasification of Biomass at Laboratory Scale," Ind. Eng. Chem. Res., 38, 2571 (1999).

Fatehi, M., and M. Kaviany, "Adiabatic Reverse Combustion in a Packed Bed," Combustion \& Flame, 99, 1 (1994).

Ghani, M. U., P. T. Radulovic, and L. D. Smoot, “An Improved Model for Fixed-Bed Coal Combustion and Gasification: Sensitivity Analysis and Applications," Fuel, 75, 1213 (1996).

Goldman, J., D. Xieu, A. Oko, R. Milne, and R. H. Esenhigh, "A Comparison of Predictions and Experiment in the Gasification of Anthracite in Air and Oxygen-Enriched/Steam Mixtures," Proc. of the 20th Int.
Symposium on Combustion, The Combustion Institute, Pittsburgh, PA, p. 1365 (1984).

Groeneveld, M. J., and W. P. M. van Swaaij, "Gasification of Char Particles with $\mathrm{CO}_{2}$ and $\mathrm{H}_{2} \mathrm{O}$," Chem. Eng. Sci., 35, 307 (1980).

Gupta, A. S., and G. Thodos, "Direct Analogy between Mass and Heat Transfer to Beds of Spheres," AIChE J., 9, 751 (1963).

Hobbs, M. L., P. T. Radulovic, and L. D. Smoot, "Modeling Fixed-Bed Coal Gasifiers," AIChE J., 38, 681 (1992).

Hobbs, M. L., P. T. Radulovic, and L. D. Smoot, "Combustion and Gasification of Coal in Fixed-Beds," Prog. Energy Combust. Sci., 19, 505 (1993).

Kashiwagi, T., and H. Nambu, "Global Kinetic Constants for Thermal Oxidative Degradation of a Cellulosic Paper," Combustion \& Flame, 88, 345 (1992).

Kayal, T. M., and M. Chakravarty, "Mathematical Modeling of Continuous Updraft Gasification of Bundled Jute Stick-A Low Ash Content of Woody Biomass," Bioresour. Technol., 49, 61 (1994).

Kurkela, E., P. Stahlberg, P. Simell, and J. Leppalahti, "Updraft Gasification of Peat and Biomass," Biomass, 19, 37 (1989).

Leach, S. V., J. L. Ellzey, and O. A. Ezekoye, "Convection, Pyrolysis, and Damkohler Number Effects on Extinction of Reverse Smoldering Combustion," Proc. of the 27th Int. Symposium on Combustion, The Combustion Institute, Pittsburgh, PA, p. 2873 (1998).

Liden, A. G., F. Berruti, and D. S. Scott, "A Kinetic Model for the Production of Liquids from the Flash Pyrolysis of Biomass," Chem. Eng. Commun., 65, 207 (1988).

Manurung, R. K., and A. A. C. M. Beenackers, "Modeling and Simulation of an Open-Core Downdraft Moving Bed Rice Husk Gasifier," Advances in Thermochemical Biomass Conversion, A. V. Bridgwater, ed., Blackie, London, p. 288 (1994).

Monazam, E. R., and L. J. Shadle, "Predictive Tool to Aid Design and Operation of Pressurized Fixed Bed Coal Gasifiers," Ind. Eng. Chem. Res., 37, 120 (1998).

Purnomo, D., J. Aerts, and K. W. Ragkand, "Pressurized Downdraft Combustion of Wood Chips," Proc. of the 23rd Int. Symposium on Combustion, The Combustion Institute, Pittsburgh, PA, p. 1025 (1990).

Radulovic, P. T., M. U. Ghani, and L. D. Smoot, "An Improved Model for Fixed-Bed Coal Combustion and Gasification," Fuel, 74, 582 (1995).

Roberts, A. F., and G. Clough, "Thermal Decomposition of Wood in an Inert Atmosphere," Proc. of the 9th Int. Symposium on Combustion, The Combustion Institute, Pittsburgh, PA, p. 158 (1963).

Scott, D. S., J. Piskorz, M. A. Bergougnou, R. Graham, and R. P. Overend, "The Role of Temperature in the Fast Pyrolysis of Cellulose and Wood," Ind. Eng. Chem. Res., 27, 8 (1988).

Shin D., and S. Choi, "The Combustion of Simulated Waste Particles in a Fixed Bed," Combustion \& Flame, 121, 167 (2000).

Winslow, A. M., "Numerical Model of Coal Gasification in a Packed Bed," Proc. of the 16th Int. Symposium on Combustion, The Combustion Institute, Pittsburgh, PA, p. 503 (1976).

Yan, H., C. Heidenreich, and D. Zhang, "Mathematical Modeling of a Bubbling Fluidized-Bed Coal Gasifier and the Significance of the Net Flow," Fuel, 77, 1067 (1998).

Yoon, H., J. Wei, and M. M. Denn, "A Model for Moving Bed Coal Gasification Reactors," AIChE J., 24, 885 (1978).

Manuscript received Apr. 16, 2003, and revision received Dec. 18, 2003. 